\title{
Biomass Plant and Sensors Network for Process Monitoring and Energy Storage in a Superconducting Magnetic Device
}

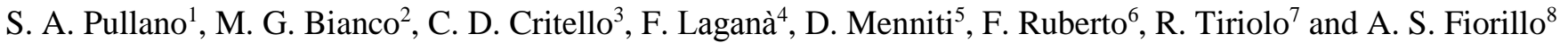 \\ ${ }^{1-8}$ University Magna Graecia of Catanzaro
}

\begin{abstract}
This research has been carried out in the context of a national organization project (PON04a2_F), promoted by the Italian Ministry of Education, University and Research under the tutelage of the European Community. It is part of a more complex "Smart Cities" project, and it is devoted to the realization of an alternative system for green energy production. It includes an electrical power supply generated from the anaerobic digestion of biomass and the storage of electrical energy in a superconducting magnetic energy storage device in order to overcome energy blackout and meet the energy needs of the network when the demand rises in closed-cycle production systems.
\end{abstract}

Keywords - Anaerobic Digester, Biomass, Energy Storage, Sensors, Smart Cities, Superconducting Device.

\section{INTRODUCTION}

In the last two hundred years, the Earth has undergone significant changes due to Mankind. Because of this, since the end of the $20^{\text {th }}$ century, the global consumption of natural resources has exceeded their availability. Human population growth has given rise to a serious problem of energy supply. Most of the world energy requirement is satisfied by fossil fuels, a non-renewable energy source.

The burning of fossil fuels results in the production of carbon dioxide and is therefore the primary source of the global greenhouse effect and warming which threaten human health.

Biomass is a renewable, perpetual energy resource, which can supply human energy needs in a sustainable way. It is defined as the biodegradable fraction of products, waste and residues of biological origin from agriculture (including vegetable and animal substances), forestry and related industries as well as the biodegradable fraction of industrial and municipal waste. Biomass is also a generic term for all vegetable materials storing solar energy through photosynthesis. During photosynthesis, the solar energy absorbed by plants is converted into carbohydrates and oxygen through the utilization of the carbon dioxide already present in the air and the water, but the use of vegetable material in the biomass transformation process can be considered an unlimited resource only if its rate of consumption does not exceed its rate of biological regeneration. Therefore, for every vegetable species used in biomass production, there is an inherent limit which depends on the size of the field in which it is grown, besides climatic and environmental variables. Therefore, biomass processing for fuel purposes requires large areas of land. Environmental conditions, such as temperature and the availability of water, also influence biomass seasonality. The use of biomass to produce energy can be considered advantageous when the growth of the vegetable species is thick and vigorous and its availability during the year is sufficiently constant. In the following, a biomass energy plant is presented. The complete system, which includes an anaerobic digester, a co-generator and a superconducting magnetic energy storage system, is monitored by a sensors network designed and realized to allow the remote evaluation of all the parameters involved in the process.

\section{ENERGY AND RENEWABLE SOURCES}

Only $13.3 \%$ of the energy produced on Earth comes from renewable sources. Fossil products (such as petroleum, coal and natural gas) plus nuclear sources meet $81.6 \%$ and $5.1 \%$ of worldwide energy needs, respectively, see Fig. 1.

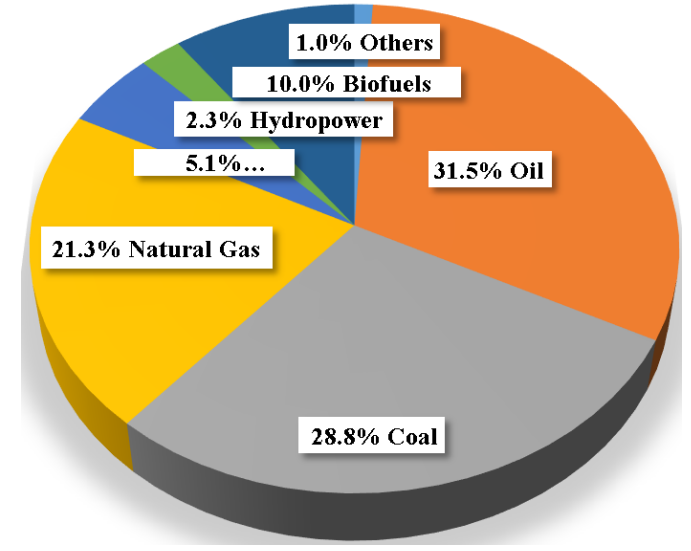

Fig. 1. The panel depicts the most important sources of primary energy used on Earth in 2010.

About $75.2 \%$ of the total primary energy production from renewable sources comes from biomass as shown in Fig. 2.

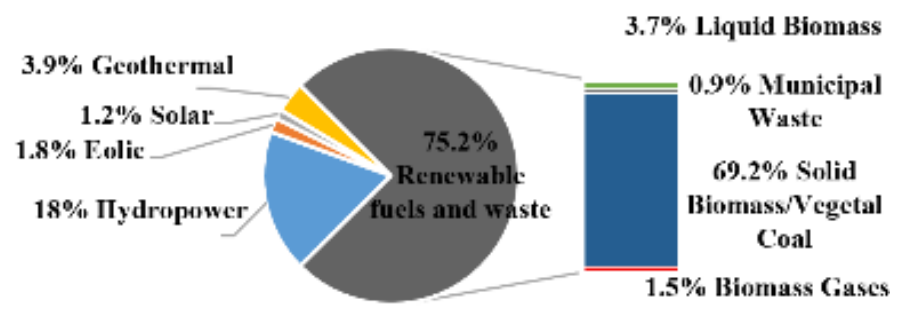

Fig. 2. Percentage distribution among renewable energy sources in 2011 
Biomass solves the problem of waste disposal and reduces net carbon dioxide emissions. Despite its benefits to the environment, using biomass is an expensive method of producing energy. Biomass is a raw material which can be converted into gas, liquid and solid energy, and then further processed in order to generate electricity and heat. Biomassto-energy conversion technologies include direct combustion, co-combustion, cultivated biomass-to-liquid fuel conversion, and biogas production. Direct combustion of biomass produces heat for industrial and domestic use, electricity and gas which can be used as a driving force. In co-combustion, in plants dedicated to the generation of electricity, certain vapors and concrete can partially replace coal dust.

Animal and vegetable biomass can produce biogas through a process known as anaerobic digestion. In the absence of oxygen, microorganisms break down organic materials into simpler forms of matter, giving off a mixture of methane and carbon dioxide which can be purified to achieve higher methane concentrations. Biogas is generally used to produce electricity and heat, but since methane is a much more effective greenhouse gas than carbon dioxide, it is important that no leakage occurs during production and distribution. Methane can be produced using biogas generators able to convert plant and animal waste into energy.

The biological reactions that occur during biomass transformation take place inside digesters (anaerobic reactors), where the monitoring of specific parameters is required in order to ensure the necessary conditions for the working of the entire system while at the same time maximizing efficiency.

In order to monitor the processes involved in the storage and digestion of the biomass that produces biogas, a remote monitoring system maintains the working conditions and provides a warning if the specified conditions become altered. Parameter monitoring is carried out in the liquid and gas phases, ensuring early detection of changes in the parameters that are indicators of the proper process of digestion. The control system also calibrates the organic load in the digester based on the parameters. The basic characteristics of a sensorial monitoring system should include the determination of the concentrations of alkalinity, $\mathrm{pH}$, fatty acids, and ammonia. Another very important parameter is that of volatile fatty acids (VFAs), the accumulation of which is indicative of some type of instability occurring in the process. These parameters are normally monitored by infrared spectroscopy (NIRS), by an electronic nose, by gas chromatography and by means of biosensors.

The measurement of the concentration of biogas produced is a reliable method of monitoring the digestion phase. Thermal conductivity sensors are used for separate measurements of methane and carbon dioxide; these are composed of two thin coils covered with platinum and are relatively fragile.

The infrared sensors are used to simultaneously assess the concentration of methane and carbon dioxide, even though they are very expensive and require a complex electronic configuration. In order to monitor a process of the anaerobic digestion of waste of food origin, it is sufficient to provide for the evaluation of parameters such as temperature and alkalinity, besides the concentration of ammonia and VFAs.

\section{BIOMASS PLANT STRUCTURE}

\section{A. Production Chain}

Biogas plants comprise several technological components divided into operational units.

i. Substrate supply system. This unit controls biomass reception, storage and introduction into the digester. The first step of biomass processing, which this component manages, consists of the pre-mixing, weighing and control of organic matter. The most important components in this unit are tanks, pumps and conveyors.

ii. Anaerobic digester. It consists of one or more covered tanks (steel or reinforced concrete), a heating system, mixers and safety valves.

iii. Biogas purification. Before it can be utilized, biogas needs to be filtered, desulphurized and dehumidified.

iv. Biogas use. This unit is composed of cogeneration- (engine, alternator and exchanger) and gas-compression equipment, a control system and an emergency burner (torch).

v. Electrical installation and connection to the network. These units convey the produced electricity supply to the distribution network, and include a transformer substation and counters.

vi. Automation and control tools. A biogas plant contains a control unit for supplying the energy needed for the operation of the plant itself, which allows both manual and automatic functioning. In addition, it can be used to monitor plant operation and display data.

vii. Digestate storage and treatment systems. Finally, there are the storage tanks and any systems necessary for the treatment of the compost (e.g. solid / liquid separator).

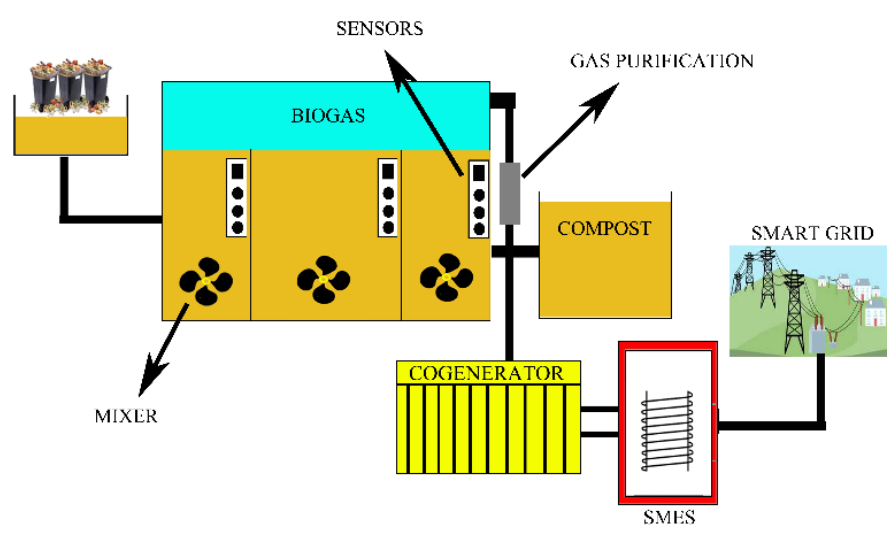

Fig. 3. Production process of a biomass plant.

Anaerobic digester reactors are made of the reinforced concrete or steel, and include several components designed to re-create the ideal conditions for the biochemical reactions that lead to the production of biogas. The most important components are:

i. Heating systems. Used to maintain a constant temperature within the operating range. This system consists of a series of pipes arranged along the inner walls or outside 
of the digester, in which hot water coming from the thermal energy produced by cogeneration circulates.

ii. Mixing system (shovel, propeller or hydraulic). Is responsible for the uniformity of the temperature inside the reactor and the mixing of the substrate, which is necessary in order to obtain a homogeneous mixture during fermentation, avoiding the formation of layers and facilitating the ascent of the biogas.

iii. Insulation. In order to limit heat dispersion as much as possible, the outside walls of the digester are covered with insulating materials, such as expanded polystyrene. As an alternative to this insulation, the reactor can be buried (if ground conditions permit).

iv. Gasometric coverage. The produced biogas is retained in the upper part of the digester, between the liquid surface and the cover. The reactor roofs may be fixed or mobile. The most popular choice is a mobile covering, usually made of polymeric material, because it allows for a variable volume.

\section{B. Anaerobic Digestion Process}

i. Anaerobic digestion is a biological process in which the degradation of organic matter in an oxygen-free environment is caused by bacteria. Anaerobic processes can also occur naturally in some environments, and this fact has resulted in the development of methods of methane collection. Sugars present in sugarcane and corn starch are fermented in order to produce bioethanol, an alcohol fuel which can be used directly, to produce electricity, or as a gasoline additive. Other options for converting biomass into energy are gasification and pyrolysis.

ii. Gasification is a process that converts lignocellulosic biomass, agricultural residues and municipal waste into a fuel gas. This is achieved by subjecting the material to high temperatures under a controlled amount of oxygen. The resulting gas can generate electricity in internal combustion engines and gas turbines.

iii. Pyrolysis is the thermal decomposition of lignocellulosic biomass in the absence of oxygen. This process produces more useful fuels, such as easy-to-transport bio-oils, coal to cook food and biofuels for use in internal combustion engines which use gasoline and diesel fuels.

The degradation of organic substances and their subsequent conversion into biogas can vary from $40 \%$ to over $95 \%$, depending on the type of biomass used, the processing conditions and the time necessary for the degradation process. Biomass that is rich in fats and proteins, as compared to carbohydrate-rich biomass, has a positive effect on the production of methane. Anaerobic digestion involves different microbic groups interacting with each other which include hydrolytic bacteria, acidifying bacteria (acetogenic and homoacetogenic) and methanogenic bacteria which are responsible for producing methane and $\mathrm{CO}_{2}$. The microorganisms, which cause the biological degradation of organic matter, according to the temperature range in which they act, are divided into Psychrophilic (temperatures below $20^{\circ} \mathrm{C}$ ); Mesophilic, (temperatures ranging from $25^{\circ} \mathrm{C}$ up to $45^{\circ} \mathrm{C}$ ) and Thermophilic, (temperatures above $45^{\circ} \mathrm{C}$ ).

Due to the slowness of the anaerobic reactions in the psychrophilic field (temperatures $<20^{\circ} \mathrm{C}$ ), the process is normally performed in mesophilic $\left(30^{\circ} \mathrm{C}-35^{\circ} \mathrm{C}\right)$ or even thermophilic (efficient values around $55^{\circ} \mathrm{C}-60^{\circ} \mathrm{C}$ ) ranges.

Methane-producing bacteria can only live in an anaerobic environment with humidity content of at least $50 \%$ in the substrate, and they also require continuous monitoring and control of the following parameters:

i. Retention time: The retention time is the time interval during which the substrates must stay in the digester. The retention time required for the optimal production of biogas depends on the temperature. In fact, considering the production of biogas close to the theoretical maximum, the temperature range of psychrophilic production requires a retention time of $40-100$ days, that for mesophilic production requires a retention time of 25-40 days and the elevated temperature range necessary for thermophilic production makes only15-25 days of the retention time necessary;

ii. $p H$ : The $\mathrm{pH}$ value in the anaerobic digester should be around 7.5. Particular attention must be given to this aspect in case of co-digestion of acid substrates;

iii. Organic load. Bacteria require a minimum organic load as 'food' for survival. Specifically, the amount of substrate should be in the range from $0.5 \mathrm{~kg}$ up to $5 \mathrm{~kg}$ of organic matter for each $\mathrm{m}^{3}$ of a digester tank per day;

iv. Auxiliary substances. Bacteria need such substances as soluble nitrogen compounds and minerals for their metabolism;

v. Nitrogen content. The presence of nitrogen in the substrate is necessary because it is a fundamental element for the metabolism of bacteria, helping to maintain a neutral $\mathrm{pH}$. However, too much nitrogen in the substrate can lead to an excessive formation of ammonia, resulting in toxic effects. An optimal carbon-nitrogen ratio $(\mathrm{C} / \mathrm{N})$ is in the range of between 20:1 and 40:1, although the most extreme values can still produce an efficient process of digestion. Emissions from the plant into the atmosphere are essentially due to the exhaust fumes coming from the cogenerator. Generally, the emissions originate from combustion and are composed of water vapor $\left(\mathrm{H}_{2} \mathrm{O}\right)$ and carbon dioxide $\left(\mathrm{CO}_{2}\right)$, to which substantially small amounts of oxides of nitrogen (NOx), carbon monoxide (CO) and total organic carbon (TOC) are added. In Italy, emission limits for cogeneration plants fueled with biogas have been established by the Legislative Decree of April 3, 2006, n. 152 under "Environmental Regulations". The values refer to one hour of plant operation in the most severe operating conditions (excluding periods of startup, shutdown and malfunctions) and to the volume of dried gas effluent related to normal conditions. 
TABLE I

PART OF ITALIAN LegISLATIVE DECREE N. 152/2006 ON EMISSION LIMITS FOR INTERNAL COMBUSTION ENGINES FUELED By BIOGAS (HOURLY MEAN VALUES).

\begin{tabular}{ccc} 
& \multicolumn{2}{c}{ Total thermal power $[\mathbf{M W}]$} \\
\cline { 2 - 3 } & $\mathbf{3}$ MW & $>\mathbf{3}$ MW \\
\hline $\begin{array}{c}\text { Total Organic Carbon }(\mathrm{TOC}) \\
{\left[\mathrm{mg} / \mathrm{Nm}^{3}\right]}\end{array}$ & 150 & 100 \\
\hline Carbon Monoxide $\left[\mathrm{mg} / \mathrm{Nm}^{3}\right]$ & 800 & 650 \\
\hline Nitrogen Oxides $\left[\mathrm{mg} / \mathrm{Nm}^{3}\right]$ & 500 & 450 \\
\hline $\begin{array}{c}\text { Inorganic compounds of chlorine in } \\
\text { gas or vapor forms }\left[\mathrm{mg} / \mathrm{Nm}^{3}\right]\end{array}$ & 10 & 10 \\
\hline
\end{tabular}

Depending on the type of gas to be analyzed, there are different kinds of sensor systems. For carbon monoxide and nitrogen dioxide an electrochemical cell is normally used; total organic carbon, however, is determined according to the presence of volatile organic compounds (VOCs) through the use of a photoionization detector (PID).

Another relevant aspect to consider during the monitoring of a biomass energy plant is the analysis of all the parameters involved in the inhibition of bacterial growth, which can limit the transformation of the substrate inside the anaerobic digestion system into the final product. Methanogens are one of the most important microorganisms, which take part in the conversion of organic compounds into methane and are characterized by a slow growth rate. Substances such as heavy metals, salts, residues of pesticides and pharmaceutical products, solvents, etc., can adversely affect the whole process of anaerobic digestion. Moreover, the substrate itself can be a limiting factor because it is able to influence the successive stages of the digestion process.

Attention should be paid to the monitoring of some metabolic intermediates such as propionate, which is a quantitatively important intermediate in anaerobic digesters. Although the concentration of propionate is usually quite low, an increase can prove to be toxic. The toxicity limit for propionate appears to be around $3 \mathrm{~g} / \mathrm{l}$. The degradation of propionate is also influenced by hydrogen which can inhibit the microbial degradation of ethanol and, reversibly, the growth of abundant anaerobic bacteria. Along more general lines, it has been reported in literature that high concentrations of volatile fatty acids (VFAs) can also have toxic effects, mainly due to the resulting decrease in $\mathrm{pH}$.

\section{Storage System}

The increasing demand for a high-quality power supply has resulted in a growing interest in the use of high-performance energy storage technology. Superconducting magnetic energy storage (SMES) is able to store considerable amounts of energy within the magnetic field created by an electric current flowing through a superconducting coil maintained below the temperature of superconductivity by means of a cryogenic liquid, as shown in Fig. 4. The stored energy is instantly available in the form of electricity and may be unloaded from the superconducting ring at an efficiency of over $95 \%$ of the whole charge/discharge cycle.

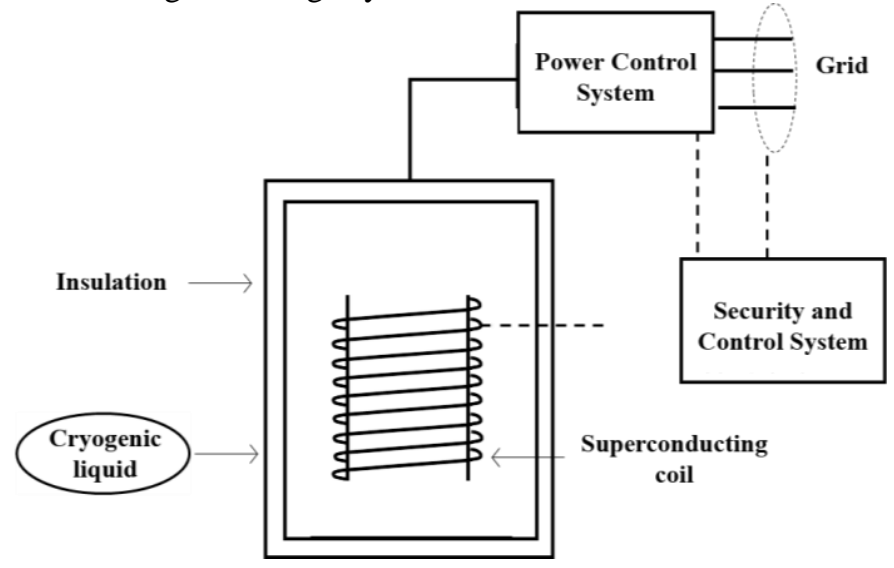

Fig. 4. Block diagram of a SMES system.

The two main blocks of the system are the superconducting coil and the cryogenic cooling system. The coil requires the presence of a magnet designed and built to work at cryogenic temperatures. In this way, the critical temperature of the coil, that is, the temperature of transition between the normal and the superconducting state can be maintained within a controllable range. Also, the critical current, which defines the maximum current of transition from the normal to the superconducting state, can be raised to increase the performance of the storage system.

The cryogenic cooling techniques are usually based on nitrogen- or liquid-helium-bath systems, even though the experimental closed-cycle system under investigation allows the achievement of high performance with minimum energy consumption, avoiding contact between the superconducting material and the coolant. Finally, close attention is also paid to the sensors and electronic control systems with a view to reducing losses which, although minimal, may affect the efficiency of the system.

The coil is made of Magnesium Diboride $\left(\mathrm{MgB}_{2}\right)$, the characteristics of which are reported in the table below.

TABLE II

MAIN PROPERTIES OF $\mathrm{MgB}_{2}$ CONDUCTOR

\begin{tabular}{c|c}
\hline Radius & $1.13 \mathrm{~mm}$ \\
\hline Number of filaments & 36 \\
\hline Composition & Ni $70 \%, \mathrm{Cu} 20 \%$ \\
\hline Critical Current @ 22 K & $550 \mathrm{~A}$ \\
\hline
\end{tabular}

In the presence of a magnetic field, this material can withstand higher temperatures without compromising the operation of the device while subjecting it to less stress.

\section{Smart Grid}

The smart grid is the evolution of the traditional electrical network in which a set of advanced sensors and communication, control and measurement systems work together to monitor the flow of energy with the aim of overcoming the variability of consumption demands. The implementation of the new-generation smart grid networks comes in conjunction with the growing demands for electricity 
that cannot be met by the enlargement of the old electrical networks, due to economic and environmental problems.

The technology that drives the new smart grids makes the integration of renewable energy sources of different origins possible, which, because of their dependence on variable phenomena, are discontinuous over time. An example of this is thermal or photovoltaic energy which depend on solar energy, the availability of which is variable. Another would be eolic energy, which is also inconstant. Balanced use of these electrical resources through the processing of information coming from all generators and loads under continuous monitoring by the network allows the necessary energy needs to be met when required, in real time.

A case in point is the management of a sudden drop in voltage by taking current from other districts that are having a low absorption or that can store energy, such as in the case of those with an SMES system. To this end, sensor networks connected to a remote monitoring system play a role of primary importance, allowing the reduction and in some cases the elimination of the load losses of the network and also of the possible interruption of the supply of energy.

\section{TOXICITY}

The analyses of different chemical species present in the biomass energy plant have been taken into consideration because of their potential toxicity. Carbon monoxide (CO) is a colorless, odorless, inflammable, highly toxic substance. It is formed during the combustion of organic substances, when the combustion is incomplete due to lack of oxygen. The great danger and toxicity of this gas is caused by its affinity with hemoglobin, which appears to be about 200-300 times greater than that of oxygen. This feature allows $\mathrm{CO}$ molecules to bind easily with the hemoglobin in the blood and thus hinder the oxygenation of the tissues, muscles and brain, resulting in acute effects (fatigue, drowsiness, headache) and in the long run chronic effects (decrease in physical and intellectual performance and increased heart disease and circulatory disorders). Nitrogen dioxide $\left(\mathrm{NO}_{2}\right)$ is a reddish brown, pungent, highly toxic, corrosive gas. It is a secondary pollutant of limited toxicity that is produced by the oxidation of nitrogen monoxide. The inhalation of nitrogen dioxide causes severe irritation of the airways. Continuous exposure to high concentrations may cause bronchitis, pulmonary edema, and emphysema. The presence of $\mathrm{NO}_{2}$ contributes to the formation of photochemical smog, as a precursor of tropospheric ozone, and contributes to the phenomenon of acid rain by reacting with water and giving rise to nitric acid. As for oxides of nitrogen, inorganic compounds of chlorine (e.g. hydrochloric acid $\mathrm{HCl}$ ) contribute to the formation of acid rain and its consequences on the environment. Hydrochloric acid is a highly irritating compound; in fact, acute exposure can cause irritation of the conjunctiva and mucous membranes. However, no known chronic effects have been observed. As far as the total organic carbon (TOC) is concerned, since this item encompasses a very composite group of possible organic molecules, a precise description of the effects of these molecules on health is practically impossible. Some hydrocarbons are not characterized by a particular toxicity (methane, propane, etc.), while others have an especially irritating action (aldehydes), and still others are characterized by a high level of toxicity with known genotoxic, immunotoxic and carcinogenic effects, including PAHs (Polycyclic Aromatic Hydrocarbons) and benzene. It is interesting to note that most toxicological action is possible because these compounds are adsorbed onto dust or particulate matter which then acts as a substrate transport and allows their introduction into the lungs.

\section{MONITORING SYSTEM}

The necessary biological reactions take place inside digesters (anaerobic reactors), where the monitoring of specific parameters is required, in order to ensure the optimal conditions for the working of the entire system. Specifically, the main process parameters to be controlled are:

i. Temperature has important effects both on the physicalchemical characteristics of the biomass in the digester and on the microorganisms. For example, it affects the kinetics of the process along with the selection of the bacteria capable of operating in the temperature range selected. It is recommended that temperature fluctuations greater than $\pm 1{ }^{\circ} \mathrm{C}-2{ }^{\circ} \mathrm{C}$ within the chosen temperature range be avoided, because even small changes can significantly affect the outcome of the process.

ii. Volatile Fatty Acids (VFAs) are organic acids produced during the degradation of organic matter. The concentration of VFAs is expressed as the concentration of acetic acid in the material volume $(\mathrm{mg} / \mathrm{L})$; it depends on the quantity and the quality of the material loaded into the digester, as well as on the balance between acidogenic and methanogenic bacteria.

iii. Alkalinity represents the system's ability to accept protons, and it is expressed as the concentration of calcium carbonate. The alkalinity of an anaerobic digester is determined by the coexistence of ammonia, originating from protein degradation, and bicarbonate, derived from the dissolution of carbon dioxide in the medium, forming a system able to buffer the lowering of the $\mathrm{pH}$ due to the accumulation volatile fatty acids.

iv. Ratio VFA/Alkalinity. The concentration of VFAs and alkalinity are two parameters which are very sensitive to changes in the system, and their ratio is a diagnostic parameter indicating possible conditions of instability. Values of around 0.3 indicate stable operation of the digester, while higher values indicate the accumulation of VFAs and the onset of stability problems. The VFA/Alkalinity ratio has diagnostic significance because it describes the dynamics going on between material already digested (alkalinity represented by ash and ammonia) and new degradation (VFAs). High VFA/total alkalinity ratio values often indicate an overload of the digester.

v. The Carbon / nitrogen ratio $(C / N)$ in the biomass must be between 20 and 40 in order to avoid deficiency or excess of nitrogen. 
vi. Concentration of ammonia. Ammonia is produced during the degradation of proteins. A high concentration of ammonia can inhibit both methanogenic and acidogenic bacteria.

Concentration ranges:

- $200-1,500 \mathrm{mg} / \mathrm{L}$ (never toxic);

- $1,500-3,000 \mathrm{mg} / \mathrm{L}$ (inhibitory if the $\mathrm{pH}$ is below 7.4);

- 3,000 mg/L (always inhibitory).

However, the presence of ammonia is important because it buffers the system inside the digester and it compensates for the accumulation of VFAs, maintaining a stable $\mathrm{pH}$.

vii. $p H$. This value depends on such parameters as the concentration of VFAs, ammonia and alkalinity. In a stable digester the $\mathrm{pH}$ value should be around $6.5-8$. If the $\mathrm{pH}$ value falls below 6.5 , then an accumulation of VFAs has occurred, often because the digester has been overloaded.

The gas produced during anaerobic digestion consists mainly of a mixture of methane $\left(\mathrm{CH}_{4}\right)$ and carbon dioxide $\left(\mathrm{CO}_{2}\right)$ with small amounts of other gases, including hydrogen sulfide $\left(\mathrm{H}_{2} \mathrm{~S}\right)$, hydrogen $\left(\mathrm{H}_{2}\right)$, nitrogen $\left(\mathrm{N}_{2}\right)$, and low molecular weight hydrocarbons. Typically, the bioreactor contains $50 \%-75 \%$ methane and $25 \%-50 \%$ carbon dioxide; the remaining gases are present in very small quantities. The composition of the biogas can vary in terms of concentration depending on the raw material used and the operating conditions.

TABLE III

BIOGAS COMPOSITION

\begin{tabular}{l|c}
\hline \multicolumn{1}{c|}{ Component } & Volume percentage \\
\hline Methane $\left(\mathrm{CH}_{4}\right)$ & $50 \%-80 \%$ \\
\hline Carbon Dioxide $\left(\mathrm{CO}_{2}\right)$ & $50 \%-20 \%$ \\
\hline Nitrogen $\left(\mathrm{N}_{2}\right)$ & $<1 \%$ \\
\hline Hydrogen $\left(\mathrm{H}_{2}\right)$ & $<1 \%$ \\
\hline Ammonia $\left(\mathrm{NH}_{3}\right)$ & $<1 \%$ \\
\hline Hydrogen sulphide $\left(\mathrm{H}_{2} \mathrm{~S}\right)$ & $<1 \%$ \\
\hline
\end{tabular}

Since biogas is normally made up of a mixture of gasses, its characteristics must be evaluated in each individual case. However, in many instances, the physical characteristics of the three main constituents, namely, methane, carbon dioxide and hydrogen sulfide, can be used to characterize the biogas.

The temperature of biogas is measured by a stainless steel electrode sensor, which is installed on the wall of the bioreactor, and measures a range of values between $-40{ }^{\circ} \mathrm{C}$ and $135^{\circ} \mathrm{C}$. The probe consists of a $20 \mathrm{k} \Omega$ thermistor, a variable resistor the resistance of which decreases nonlinearly with increasing temperatures.

The interface measures the value of resistance $(R)$ at a certain temperature and converts the resistance using the Steinhart-Hart equation:

$$
T=\left[A_{0}+A_{1}(\ln 1000 R)+A_{2}(\ln 1000 R)^{3}\right]^{-1}-273.15
$$

where $T$ is the temperature, $R$ is the resistance and $A_{0}, A_{1}$ and $A_{2}$ are constants.

The alkalinity of the substrate can be measured by the use of laboratory instrumentation, such as titration, infrared spectroscopy and liquid or gas chromatography. Before being sent to a laboratory for analysis, the sample is pre-treated with reagents. There are also indirect methods to measure the value of alkalinity that make use of sensors and calculation software, and measurements are obtained in real time. This monitoring system uses three types of sensors, $\mathrm{pH}$, redox potential, and electrical conductivity, which are installed on the wall of the bioreactor. The data are displayed, stored, and processed by software for the calculation of the alkalinity level, according to the following equation:

$$
\text { alk }=-8906+(1678 \cdot \mathrm{pH})+(1.998 \cdot \text { redox })+(384.2 \cdot \mathrm{EC})
$$

The probe that detects the $\mathrm{pH}$ is a sensor electrode characterized by a double junction and a polycarbonate body equipped with a flat glass membrane which makes it durable and easy to clean. The $\mathrm{pH}$ probe measures values between 0 and 14. The probe which measures electrical conductivity in order to determine the ionic content of an aqueous solution is characterized by three ranges of work:

Low Range: 0 to $200 \mu \mathrm{S} / \mathrm{cm}$ (0 to $100 \mathrm{mg} / \mathrm{L}$ TDS $)$

Mid Range: 0 to $2,000 \mu \mathrm{S} / \mathrm{cm}$ (0 to $1,000 \mathrm{mg} / \mathrm{L}$ TDS)

High Range: 0 to $20,000 \mu \mathrm{S} / \mathrm{cm}$ (0 to $10,000 \mathrm{mg} / \mathrm{L}$ TDS $)$

This probe measures the ability of a solution to conduct electric current between two electrodes expressed in Siemens. The characteristic equation of operation of the probe is:

$$
C=G K_{C}
$$

where $C$ is the electric conductivity, $G$ is the conductance and the cell constant $K c$ is defined by the ratio between (distance between the two electrodes)/(surface values of the electrodes). The oxidation reduction potential (ORP) probe is composed of electrodes that measure the capacity of a solution to act as a reductant or oxidant. The electrodes are composed of a platinum part immersed in the solution in which the oxidationreduction reaction takes place, and another part in which the platinum electrode is immersed in a solution of silver chloride which is used as a reference. The probe can measure the redox potential between $-450 \mathrm{mV}$ and $1100 \mathrm{mV}$. The probe that assesses the concentration of ammonia in the bioreactor is made of an ion-selective membrane electrode specific for ammonium $\mathrm{NH}_{4}$ (ISE). When this membrane electrode comes in contact with a solution containing specific ions, it develops a voltage which depends on the concentration of ions in the solution.

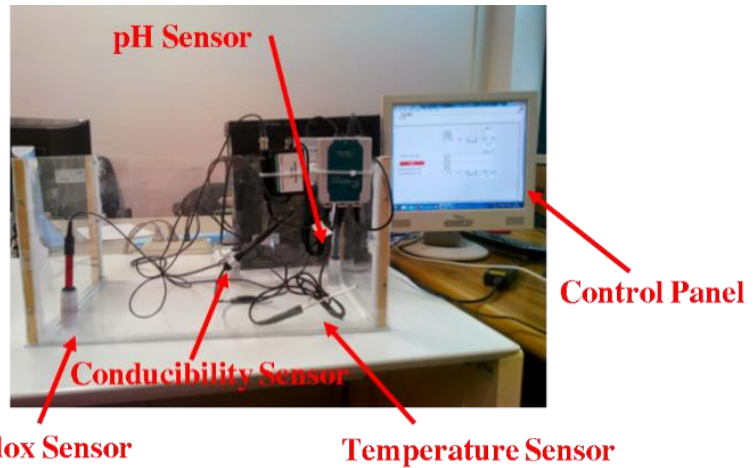

Fig. 5. Experimental digester remote monitoring system. 
The data measured by the sensors are sent to a personal computer by means of a specific transmitter. The transmitter is an interface that connects the probes through a pre-amplifier and a British Telephone (BT) connector to a computer through a USB port that has the task of processing the data.

Tank-level monitoring was accomplished through the design and realization of a sonar system, which included the fabrication of both transmitter and receiver made in our laboratory with a sheet of polyvinylidene- fluoride (PVDF) as shown in Fig. 6.

\section{US Transducer}

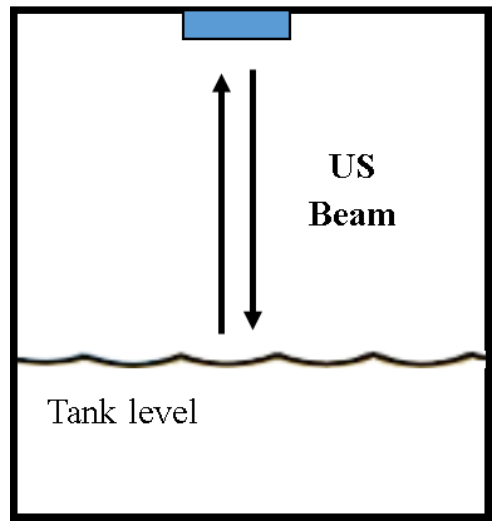

Fig. 6. Tank level monitoring based on PVDF transducer.

By applying an alternating voltage between the two electrodes, the semi-cylindrical geometry and its lateral constraint allows the conversion of longitudinal motion into radial vibration. The PVDF transducer is shown in Fig. 7. It has been properly designed to work in hazardous environments and was fabricated in cooperation with the BATS Company, s.r.l.

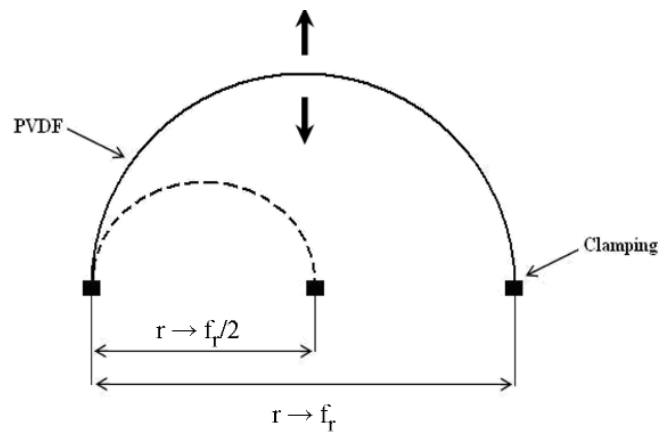

Fig. 7. Piezo-polymer film transducer obtained by curving a PVDF resonator.

The resonance frequency is inversely proportional to the bending radius and can be easily controlled by varying it. Neglecting the clamping effects, the resonance frequency is given by:

$$
f=\frac{1}{2 \pi r} \sqrt{\frac{1}{\rho s_{11}^{E}}}
$$

where $r$ is the radius of the curvature and $1 / s_{11}^{E}$ and $\rho$ are Young's modulus and mass density of curved PVDF film material, respectively. The system includes an operational power amplifier chosen to design a specific electronic circuit capable of driving the PVDF transducer over a wide band around the resonance easy assembled in portable instrumentation or mounting on mobile robots. Because of the ferroelectric polymer's inherent noise, the correct modelling of the transducer's electrical impedance plays an important role in designing the electronic circuits. The actual custom transmitter concentrates all its energy in the frequency band of the transducer. The sonar system makes use of a high performance hemi-cylindrical PVDF transducer working at 60 $\mathrm{kHz}$ for the evaluation of the time of flight (TOF) by using the cross correlation algorhythm.

The concentration of VFAs can be measured using spectroscopic or more innovative techniques, such as the electronic nose or biosensors.

The methods of on-line detection of VFAs are divided into three categories: the titrimetic method, the optical method and the sensor/biosensor.

The more reliable methodologies are those which require the use of laboratory instrumentation, such as spectroscopy, which are able to determine the concentration of individual acids besides that of the total concentration.

In the recent years, however, methods that make use of electronic noses have been successfully used experimentally in bioreactors and also in the titration laboratory.

Today, however, the use of biosensors is still in the testing phase. These are based on bacterial and other enzymes which can be used to determine the total concentration of VFAs.

\section{CONCLUSION}

This article describes a smart exploitation of biomass for the production of renewable energy in a small rural community in south Italy. The relatively new technology of SMES partially increases the cost of the system aimed at providing energy for short electrical blackout, which can be experienced on the power grid. However, its cost is justified in the situation in which a big plant such as a refrigerator for the storage of vegetables, meat and fish or drugs and other biomedical supplies needs a continuous supply of energy. The actual system furnishes $10 \mathrm{~kW}$ of power for 1 minute but if the SMES cost is lowered (only 10 medium size SMES are efficient at present in various laboratory around the world for research purposes), the production of systems capable to deliver electrical power of some $\mathrm{kW} / \mathrm{h}$ from renewable sources, such as biomass, will be easier and more convenient.

\section{ACKNOWLEDGEMENT}

The authors are grateful to BATS s.r.l. for its support in the production of sensors. This work was done in the context of the national scientific project PON04a2_F for the European Community which is supported by the Italian Ministry of Education, University and Research.

\section{REFERENCES}

[1] International Energy Agency (IEA) - Key World Energy Statistics, 2013. [Online]. Available: http://www.iea.org/.

[2] International Energy Agency (IEA) - Key World Energy Statistics, 2012. [Online]. Available: http://www.iea.org/.

[3] A. S. Dhoble, P. C. Pullammanappallil, "Design and operation of an anaerobic digester for waste management and fuel generation during 
long term lunar mission", Advances in Space Research, vol. 54 pp. 1502-1512, 2014. http://dx.doi.org/10.1016/j.asr.2014.06.029

[4] T. Lienen, A. Kleyböcker, W. Verstraete, H. Würdemann, "Moderate temperature increase leads to disintegration of floating sludge and lower abundance of the filamentous bacterium Microthrix parvicella in anaerobic digesters", Water Research, vol. 65, pp. 203-2012, Nov. 2014. http://dx.doi.org/10.1016/j.watres.2014.07.019

[5] B. Subramanian, K. R. Pagilla, "Anaerobic digester foaming in full-scale cylindrical digesters - Effects of organic loading rate, feed characteristics, and mixing," Biosource Technology, vol. 159, pp. 182-192, May 2014 http://dx.doi.org/10.1016/j.biortech.2014.02.089

[6] F. X. Collard, J. Blin, "A review on pyrolysis of biomass constituents: Mechanisms and composition of the products obtained from the conversion of cellulose, hemicelluloses and lignin," Renewable and Sustainable Energy Reviews, vol. 38, pp.594-608, 2014. http://dx.doi.org/10.1016/j.rser.2014.06.013

[7] M. Asadullah, "Biomass gasification gas cleaning for downstream applications: A comparative critical review," Renewable and Sustainable Energy Reviews, vol. 40, pp. 118-132, 2014 http://dx.doi.org/10.1016/j.rser.2014.07.132

[8] A.S. Fiorillo, "Design and characterization of a PVDF ultrasonic range sensor," IEEE Transaction on Ultrasonics., Ferroelectrics and Frequency Control, vol. 39, no. 6, pp. 688-692, Nov. 1992. http://dx.doi.org/10.1109/58.165552

[9] A. S. Fiorillo, "Ultrasound transducer with low synthetic quality factor," Applied Physic Letters, vol. 68, no. 2, 1996, pp. 164-166. http://dx.doi.org/10.1063/1.116447

[10] A. S. Fiorillo, S. A. Pullano, "Ferroelectric polymer for biosonar replica," In Ferroelectrics - Applications, Intech, 2011

[11] H. J. Jeon, Y. K. Choi, K. G. Song, S. H. Lee, Y. H. Yang, H. Kim, S. Kim, R. Kumaran, S. W. Hong, H. Joo Kim, "Development of a photoelectrochemical sensor for monitoring algal biomass (Chlorella vulgaris)," Sensors and Actuators B: Chemical, vol. 185, pp. 405-410, 2013. http://dx.doi.org/10.1016/j.snb.2013.05.026

[12] K. B. Byrd, J. L. O'Connell, S. Di Tommaso, M. Kelly, "Evaluation of sensor types and environmental controls on mapping biomass of coastal marsh emergent vegetation," Remote Sensing of Environment, vol. 149, pp. 166-180, 2014.

[13] V. Bellon-Maurel, O. Orliac, P. Christen, "Sensors and measurements in solid state fermentation: a review," Process Biochemistry, vol. 38, pp. 881-896, 2003. http://dx.doi.org/10.1016/S0032-9592(02)00093-6

[14] M. H. Ali, B. Wu, R. A. Dougal, "An Overview of SMES Application in Power and Energy Systems," IEEE Transactions on Sustainable Energy, vol. 1, no. 1, pp. 38-47, 2010. http://dx.doi.org/10.1109/TSTE.2010.2044901

Salvatore A. Pullano received the B. S. and M. S. degrees in electronic engineering from the University of Calabria, Italy, and the $\mathrm{Ph}$. D. degree in biomedical engineering and computer science from the University of Magna Græcia in Catanzaro, Italy. Currently, he is a Post-Doctoral Fellow in the Department of Health Sciences at the University Magna Græcia of Catanzaro, Italy. From 2012 to 2013, he was a visiting scholar in the Department of Electrical Engineering and Computer Science at the University of Tennessee, in Knoxville, USA. His research interests include the design of pyroelectric and piezoelectric sensors, electronic systems for biomedical data acquisition and electrical brain stimulation. He is also involved in scientific projects and interdisciplinary activities in molecular nanotechnology. He was a recipient of the fellowship for the 12th NSF International Summer School on Biocomplexity and Biodesign and serves as Junior Associate Editor of the IEEE Journal of Translational Engineering in Health and Medicine.

E-mail: pullano@unicz.it

Maria Giovanna Bianco received the B. Sc. degree in computer science and biomedical engineering, the $\mathrm{M}$. Sc. degree in biomedical engineering and the Master of Studies in biomedical electronics in 2009, 2011 and 2013 respectively from the University Magna Graecia of Catanzaro, Italy.

From 2011 to 2013, she worked as an Apprentice Engineer at Telecom Italia SpA. She is currently a Ph. D. student in biomedical engineering and computer science at the University of Magna Graecia in Catanzaro and is a visiting student at McGill University, in Montreal, Canada. Her main research interest is the study of Neural Stimulation Techniques based on biomimetic sonar, for sensorial brain information transfer.
E-mail: maria.giovanna.bianco@gmail.com

Costantino D. Critello received the Bachelor degree in biomedical engineering from the University Magna Graecia of Catanzaro, Italy, in 2011. $\mathrm{He}$ received the Master degree in biomedical electronics from the University Magna Graecia of Catanzaro in 2013. He is a Ph. D. student in biomedical and computer engineering at the same University. His research is focused on the development of low-frequency ultrasound systems in biomedicine and pharmacology with emphasis on nonlinear cavitation in biological tissue.

E-mail: davidecritello@gmail.com

Filippo Laganà received the $\mathrm{B}$. Sc. and $\mathrm{M}$. Sc. degrees in electronic engineering from the University Mediterranea of Reggio Calabria, Italy. He is currently a Ph. D. student in biomedical and computer engineering with the University Magna Graecia of Catanzaro, Italy.

E-mail: filippo.lagana@unirc.it

Daniela Menniti received the B. Sc. degree in computer science and biomedical engineering and the M. Sc. degree in biomedical engineering from the University Magna Graecia of Catanzaro, Italy, in 2009 and 2014 respectively.

Presently she is a Ph. D. student in life sciences working on electrical brain stimulation in rats through ultrasonic based signals generated in air.

E-mail: mennitidaniela@gmail.com

Francesco Ruberto received the Bachelor degree in computer science and biomedical engineering and post-graduate Master of studies cum laude, in biomedical electronics from the University Magna Graecia of Catanzaro, Italy, in 2012 and 2013 respectively.

Currently he is working toward the Master degree in biomedical engineering, and is also a laboratory assistant involved in the realization of ultrasonic systems at the same University.

E-mail: francrub@alice.it

Raffaele Tiriolo received the B. Sc. degree and M. Sc. degree in computer science and biomedical engineering from the University Magna Graecia of Catanzaro, Italy, in 2008 and 2011 respectively. He received the Master of Studies in biomedical electronics and software design and certification from the same University in 2013. From 2012 to 2013, he worked as P. M. and B. A. apprentice at Telecom Italia SPA. He is currently he a Ph. D. student with the University Magna Graecia of Catanzaro working on biosensors, nano-porous materials and the interaction with bio-molecules.

E-mail: tiriolo@unicz.it

Antonino S. Fiorillo graduated in electronic engineering in 1984 and received the $\mathrm{Ph}$. D. degree in electronic devices and technologies in 1988, both from the University of Pisa, Italy. From 1984 to 1991, he was a researcher with the "Centro E. Piaggio" School of Engineering, at the same university, where he was involved in the development of proximity and tactile sensors based on ferroelectric polymer technology for robotics and medicine. $\mathrm{He}$ was an Assistant Professor with the University of Salerno and the University of Sannio, from 1991 to 2003, when he was awarded the position of Associate Professor in electronics and sensors at the University Magna Græcia of Catanzaro, Italy, where he is presently working. He was a Visiting Scientist from 1987 to 1997, and then a Visiting Professor from 1997 to 2002 with the "Center of Sensor Technologies" of the University of Pennsylvania, Philadelphia, USA.

He is currently the director of the Veneto Research Consortium in Padova, Italy, Director of the Master Course in Biomedical Electronics, and is responsible for the national scientific PON01 and PON04 projects (20072013) for the European Community, which are supported by the Italian Ministry of Education, University and Research. He is also director of the high formation school for expert researchers in the "electronic and power systems for superconducting plants". He is an associated editor of the RTU Journal "Safety of Technogenic Environment". His primary research interests are in the area of discrete and silicon integrated sensors based on ferroelectric and conducting polymers for application in the fields of robotics and medicine, as well as electrical brain stimulation, and the interfacing of electronic and biological systems with nanoporous structure on silicon.

E-mail.nino@unicz.it 